\title{
The association between vitamin D status, muscle strength, power and cardiorespiratory fitness in adolescents from the Young Hearts Study
}

\author{
E. Carson ${ }^{1}$, L. K. Pourshahidi ${ }^{1}$, C. A. Boreham ${ }^{2}$, T. R. Hill ${ }^{3}$, K. D. Cashman ${ }^{4}$, J. J. Strain ${ }^{1}$ and \\ M. S. Mulhern ${ }^{1}$ on behalf of the Young Hearts Study Group \\ ${ }^{1}$ NICHE, University of Ulster, Coleraine, BT52 1SA, UK, ${ }^{2}$ Cardiovascular Research Centre, Queen's University, \\ Belfast, BT7 INN, UK, ${ }^{3}$ School of Agriculture, Food and Rural Development, Newcastle University, Newcastle upon \\ Tyne, NE4 5PL, UK and ${ }^{4}$ School of Food and Nutritional Sciences, University College Cork, Cork, Ireland
}

Skeletal muscle is a major target organ of the vitamin $\mathrm{D}$ endocrine system ${ }^{(1)}$. Whilst adolescence is a critical period for musculoskeletal development, few studies have investigated the effect of vitamin D status on muscle function and physical fitness in this age group $^{(2,3)}$. The aim of this study was to investigate the association between vitamin D status and muscle strength, muscle power and cardiorespiratory fitness (CRF) in adolescents.

A total of 1015, 12- and 15-y-olds from the Young Hearts Study 2000 had serum 25-hydroxyvitamin D (25(OH)D) concentrations quantified using enzyme linked immunoassay (OCTEIA ${ }^{\circledR}$, IDS, Ltd., UK). Total skinfolds were used to calculate absolute fat free mass (FFM; kg) and FFM corrected for height (fat free mass index (FFMI); $\mathrm{kg} / \mathrm{m}^{2}$ ). Sargent jump test results were used to calculate peak muscle power $(\mathrm{kW})^{(4)}$. Muscle strength $(\mathrm{kg})$ was measured by hand grip dynamometry (Takei Scientific Instrument Company Limited, Japan) and $\mathrm{VO}_{2}$ max, a measure of CRF, was estimated from 20-metre shuttle test scores.

\begin{tabular}{|c|c|c|c|c|c|c|c|c|}
\hline & \multirow{2}{*}{\multicolumn{2}{|c|}{$\frac{12 \text {-y-old boys }}{n 266}$}} & \multirow{2}{*}{\multicolumn{2}{|c|}{$\frac{12 \text {-y-old girls }}{n 260}$}} & \multirow{2}{*}{\multicolumn{2}{|c|}{$\frac{15 \text {-y-old boys }}{n 239}$}} & \multirow{2}{*}{\multicolumn{2}{|c|}{$\frac{15 \text {-y-old girls }}{n 250}$}} \\
\hline & & & & & & & & \\
\hline & $\beta$ & S.E. & $\bar{\beta}$ & S.E. & $\bar{\beta}$ & S.E. & $\bar{\beta}$ & S.E. \\
\hline \multicolumn{9}{|l|}{ Muscle strength (kg) } \\
\hline High vs. low tertile & -0.02 & $0 \cdot 72$ & 0.92 & $0 \cdot 88$ & $3 \cdot 33 *$ & 1.08 & $0 \cdot 67$ & 0.86 \\
\hline High vs. middle tertile & $0 \cdot 26$ & $0 \cdot 71$ & $0 \cdot 81$ & $0 \cdot 75$ & $0 \cdot 30$ & $0 \cdot 90$ & $0 \cdot 31$ & $0 \cdot 80$ \\
\hline \multicolumn{9}{|l|}{ Muscle power $(\mathrm{kW})$} \\
\hline High vs. low tertile & -1.63 & 1.01 & $0 \cdot 05$ & 1.04 & $-0 \cdot 56$ & 1.05 & -1.07 & 1.09 \\
\hline High vs. middle tertile & 0.77 & $0 \cdot 95$ & $-0 \cdot 35$ & $0 \cdot 88$ & $0 \cdot 34$ & $0 \cdot 97$ & -0.75 & 0.80 \\
\hline \multicolumn{9}{|l|}{$\mathrm{VO}_{2} \max (\mathrm{ml} / \mathrm{kg} / \mathrm{min})$} \\
\hline High vs. low tertile & $0 \cdot 71$ & $1 \cdot 11$ & $0 \cdot 11$ & $1 \cdot 04$ & $2 \cdot 76^{*}$ & $1 \cdot 30$ & 0.63 & 1.03 \\
\hline High vs. middle tertile & -0.09 & 1.08 & $-1 \cdot 11$ & $0 \cdot 89$ & -1.29 & $1 \cdot 15$ & 0.79 & 0.92 \\
\hline
\end{tabular}

Regression analyses to compare the relationship between tertiles of serum $25(\mathrm{OH}) \mathrm{D}$ concentration (low, middle and high) and muscle strength, muscle power and cardiorespiratory fitness $\left(\mathrm{VO}_{2} \max \right)$, controlling for season, FFMI, energy adjusted protein intake, pubertal status and physical activity scores. $* P<0 \cdot 05$.

Muscle strength and CRF were significantly higher in 15 -y-old boys in the high tertile of serum $25(\mathrm{OH}) \mathrm{D}$ concentration $(>75 \mathrm{nmol} / \mathrm{L})$, compared to those in the low tertile $(<50 \mathrm{nmol} / \mathrm{L})$. This association was not evident in any of the other age-sex groups and there were no associations between serum $25(\mathrm{OH}) \mathrm{D}$ concentration and muscle power, in any age-sex group. These results confirm the relationship between vitamin D status and muscle strength and CRF; the difference in these relationships between age-sex groups highlights a fast-changing hormone profile during adolescence and warrants further research in this age group.

This work was funded by the Department for Employment and Learning. Serum 25(OH)D analysis was funded previously by the Higher Education Authority under its North-South programme. Ethical approval was obtained from the Research Ethics Committee, Queen's University Belfast and the study was conducted according to the guidelines laid down in the Declaration of Helsinki.

1. Bischoff-Ferrari HA, Borchers M, Gudat F et al. (2004) J Bone Miner Res, 19, 265-269.

2. Hazell TJ, DeGuire JR \& Weiler HA. (2012) Nutr Rev, 70, 520-533.

3. Ward KA, Das G, Berry JL, et al. (2009) J Clin Endocrinol Metab, 94, 559-563.

4. Sayers SP, Harackiewicz DV, Harman EA, et al. (1999) Med Sci Sport Exer, 31, 572-577. 